\title{
LEGIBILITY
}

A major purpose of the Technical Information Center is to provide the broadest dissemination possible of information contained in DOE's Research and Development Reports to business, industry, the academic community, and federal, state and local governments.

Although a small portion of this report is not reproducible, it is being made available to expedite the availability of information on the research discussed herein. 


\title{
LA-UR $87-1397$
}

$$
\text { Anit. }
$$

\section{TITLE: Predicting the Production Rates of Cosmogenic}

\section{Nuclides in Extraterrestrial Matter.}

\section{DISCI.AIMER}

\begin{abstract}
This report was prepared as an acciount of work spunsored by an agency of the United States
(juvernment. Neither the United States Government nor any agency thereor, nor any of their AUTHOR(S): Robert C. Reedy employees, makes any warranty, express or implied, or assumes any legal liability or reaponsibility for the accuracy, completeness, or usefulness of any information, apparatus, product, or process disclosed, or represents that its use would not infringe privately owned rights. Reforence herein to any apecific commercial product, process, or service by trade nume, trademark. munufucturer, or otherwise doen not neceasarily constitute or imply its endorsement, recommendution, or favoring by the United Stales Government or any agency thereof. The views and opinions of authors expressed herein do not necessurily slate or reflect thuse of the United States Government or any agency thereof.
\end{abstract}

submitted to: Proceedings of the 4 th International Symposium on

Accelerator Mass Jpectrometry,

Niagara-on-the-Lake. Ontarin, 27-30 A.pril 1987. 


\title{
PREDICTING THE PRODUCTION RATES OF COSMOGENIC NUCLIDES IN EXTRATERRESTRIAL MATTER
}

\author{
Robert C. REEDY \\ - Earth and Space Sciences Division, Los Alamos National Laburatory \\ Los Alamos, NM 87545, USA
}

The production rates of nuclides made by the galactic and solar cosmic rays are important in the interpretations of measurements made with lunar samples, meteorites, and cosmic spherules. Production sates of cosmogenic nuclides have been predicted by a variety of methods that are reviewed in this paper. rarging from systematic studies of one or a group of meteorites to purely theoretical calculatiors. Production rates can vary with the chemical composition and the preatmospheric depth of the sample and with the size and shape of the object. While the production systematics for cosmogenic nuclides are fairly well known, our ability to predict their production rates can be improved, with a corresponding increase in the scientific return. Additional detailed studies of cosmogenic nuciides in extraterrestrial objects are needed, especially for lairly smail and very large objects. Nuclides made in simulation experiments and cross sections for many major nuclear raations should be measured. Such studies are especially needed for the long-lived radionuclides that have only recently become readily measurable by accelerator mass spectrometry.

\section{Int roduction}

The inner solar system not only contnins the terrestrial planets and their moons, but also a number of smaller objects and a variety of radiations. Some of these objects reach the surface of the arth without being completely destroyed, such as meteorites, cosmic dust, and cosmic spherules. In addition, lunar samples have been returned to arth hy the dpollo and Luna missions. There are a gratat variety of radiations, including some of low ancrgies (such as the solar wind) or low fluxes (such an gammat rays).

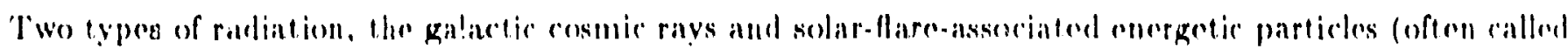

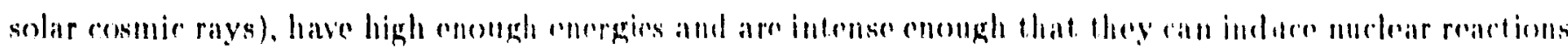

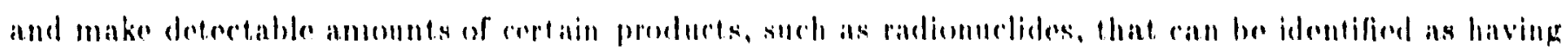
beres madre by commiceng partideles [:]. 
After the discovery of cosmic-ray-produced (cosmogenic) nuclides about 40 years ago, a wide variety of studies soon were being done with them (see historical review in ref. [2]). These studies ranged from the nature of the cosmic-ray interactions with matter to studies of the histories of the cosmic rays and of the objects themselves (see, for example, the review in ref. [1]). The initial work on cosmogenic nuclides came soon after the first high-energy (above $\sim 1$ ( $\mathrm{ieV}$ ) accelerators were built, and studies of cosmogenic nuclides made by the $\mathrm{GeV}$ protons in the galartic cosmic rays (GCR) with meteorites complimented work being done on high-energy nuclear reactions at these accelerators (e.g., the work on spallation systematics with iron by ref. [3]). Long-lived cosmogenic radionuclides showed that the intensities of GCR particles har! not varied much in the past. The lengths of time that meteorites had been exposed to cosmic rays (called exposure ages) were determined to have been $\sim 10 \mathrm{Ma}\left(10^{7}\right.$ years $)$ for stony meteorites and $\sim 100 \mathrm{Ma}$ to $1 \mathrm{Ga}$ for iron meteorites, much less than their formation ages $4.5 \mathrm{Ga}$ ago.

Very soon after the first observations of cosmogenic nuclides, several systematic studies were done with meteoritic samples that helped to establish some initial production rates of cosmogenic nuclides in meteorites. Several models were soon developed for the prediction of the production rates of cosmogenic nuclides (e.g., [4, 5]). Thick-target experiments at high-energy accelerators were also done to help in predicting, production rates of nuclides made by the (iCR (e.g., $[6,7])$. With the return of samples from the moon, the study of solar cosmir rays (SCR) and their effects in extraterrestrial matter progressed rapidly (e.g., $[8,9])$. Some production rate: of cosmogenic nuclides have been predicted using purely theoretical calculations (for example, $[10,11])$. Many models for the prediction of these production rates used a theoretical approach that was normalized to experimental data for extraterrestrial samples (such as $[4,12]$ ), and some models require a variety of basic data, such as cross sections for nuclear wactions (e.g. $[8])$.

This review of the predictions of cosmogenic nuclide production rates will consicier only i he galactic cosmir rays ( $($ C R ) and solar cosmic rays (G('R). These two types of cosmic rays different in many ways

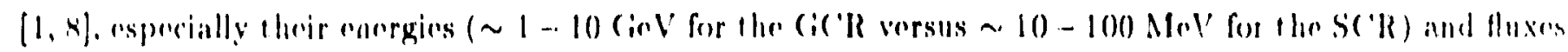

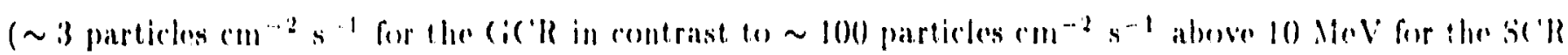

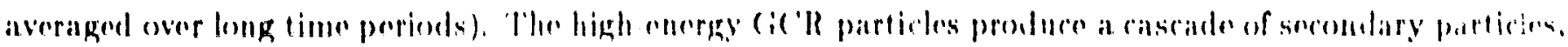

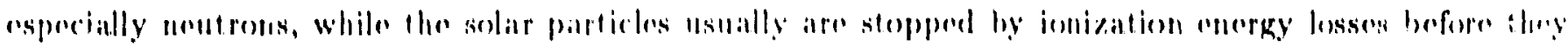

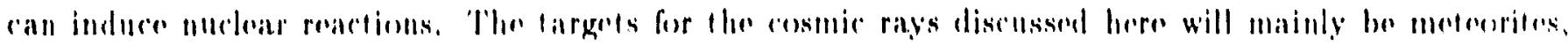


lunar samples, cosmic dust, and cosmic spherules. Only passing reference will be made to the production of cosmogenic nuclides in the earth's atmosphere and in terrestrial rocks. Because of the limitations of space for this article, only a few references will be given below, and many excellent works involving cross sections, cosmogenic-nuclide production rates, measurements of cosmogenic nuclides, and related work unfortunately can not be discussed or cited.

\section{Solar Cosmic Rays}

\subsection{Nature of SCR particles and their interactions}

The energetic particles from the sun that occasionally pass through the inner solar system have energies of $\sim 1-50 \mathrm{MeV}$ but usually not extending much above $\sim 100 \mathrm{MeV}[1,8]$. These energetic solar particle everts mainly occur when the sun is relatively active and not during periods of low solar activity $[1,8,9]$. The fluxes of particles (which are $\sim 98 \%$ protons, plus some alpha particles and a few heavicr nuclei [13]) in these events vary from barely detertable to up to $\sim 10^{6}$ protons $\mathrm{cm}^{-2} \mathrm{~s}^{-1}$ at the peak of the largest svents. Although first detected by ground-level instruments in 1942, the detailed study of SC'R particles began in the 1960s and was aided by sturlies of SCR-produced nuclides in lunar samples (cf., [1, 9]). Our main source of knowledge about these particles before the 1960 s has teen from lunar samples. As intense particle fluxes in some rare SCR events are very hazardous to men and electronics in space, the studies of aurient SCR particles from their fossil records in lunar samples have been very valuable in understanding these ellergetic particles. However, additional work is needed by doing additional measurements of SC'R. produced nuclides in lunar samples and in getting cross sections to interpret many of these measurcments. such as for ${ }^{14}\left(:[1-1]\right.$. Studies of solnr alpha particles over the last $\sim 10^{5}$ yeara using ${ }^{39} \mathrm{Ni}$ in lunar samples also could be done.

'The cnergy spertera of the SC 'R particles drerease rapidly with increasing energy. having shapess roughly'

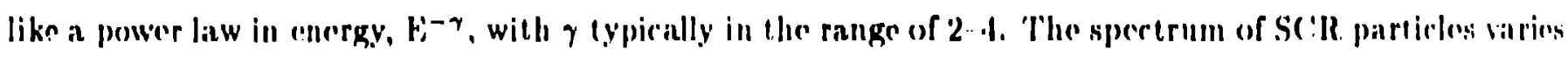

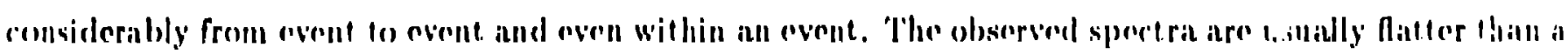

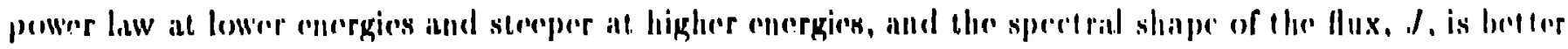
describerl as an exponential rigidlity [s].

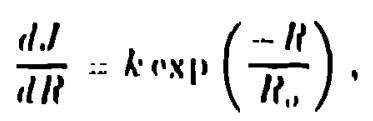


where the parameter $R_{o}$ describes the shape. Typical values of $R_{o}$ range from $\sim 35-150$ MV $[3,9]$. Over the last $\sim 10^{6}$ years, the average omnidirectional fluxes of solar protons above 10, 30,60, and $100 \mathrm{MeV}$ have been about $70,25,9$, and 3 protons $\mathrm{cm}^{-2} \mathrm{~s}^{-1}$, respectively [1].

Because the ranges of most SCR particles are much less than their nuclear interaction lengths, most SCR particles are stopped by ionization energy losses before they can react. Their ranges are short. $\sim 1 \mathrm{~g} \mathrm{~cm}^{-2}$ in silicate material, so the few reactions that they produce are mainly in the top centimeter of an extraterrestrial target $[8,10]$. The nuclear rcactions induced by SCR particles tend to be low-energy ones like ${ }^{56} \mathrm{Fe}(\mathrm{p}, \mathrm{n}){ }^{56} \mathrm{Co}$ and ${ }^{28} \mathrm{Si}(\mathrm{p}, 2 \mathrm{pn}){ }^{26} \mathrm{Al}$, and iew high-energy reactions, such as those that produce ${ }^{10} \mathrm{Be}$ from oxygen and heavier elements, are induced [8]. Relatively few secondary particles, such as neutrons. are produced in these reactions [10], so almost all nuclides are made by the primary SCR particles. SCRproduced nuclides vere ruacily observed in lunar samples because little: material had been lost by handling or by micrometeorite erosion on the lunar surface (which has rates of $\sim 1 \mathrm{~mm} \mathrm{Ma}^{-1}$ ). The outer layers of meteorites that have the SCR-produced nuclides are usually removed by ablation. Only very recently have meteorites been found that have large concentrations of SCR-produced nuclides, such as ALHA77005 [15] and Salem [16]. Concentrations of SCR-produced radionuclides should be very high in very small objects in space, such as those recovered in deep-sed sediments $[17,18]$.

\subsection{Calculations of the production rates of SCR-produced nuclides}

One of the first published results for the production rates of SCR-produced nuclides in lunar samples was the Monte Carlo ralculations of Armstrong and Alsmiller [10]. These purely theoretical calculationli started with the intranuclear cascade induced by the primary particle and followed the subsequent evaporation of particles from the excited nucleus to get the residual nucleus. All of the emitted secondary particles were tracked until they escaped from the moon or were removed by nurlear reartions or stopping. The results reproduced the lunar-sample results fairly woll. $A$ deficiency of this approach is that the code directly calculates the production of all residual nuclei without the use of any experimental rross sections. While such intranuclear-cascaule/evaporation caleulations usually work fairly woll in reproducing experimentad rrosis sections, they often fail for creft.in produrts. These calculations also ignored all incident. solar

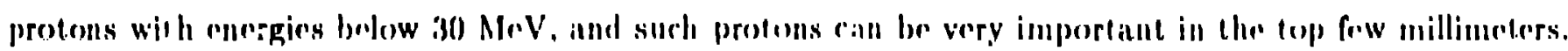

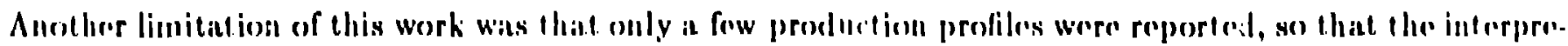

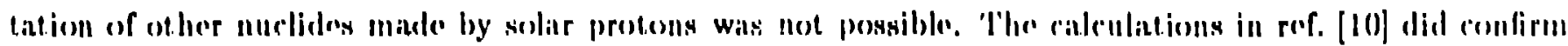


the expectation that secondary particles were relatively unimportant for the production of nuclides by the SCR particles.

The other type of model, the one that has almost always been used for calculating the production rates of nuclides by SCR particles, ignores secondary particles and only follows the primary particles. The first published paper using this approach for lunar samples was by Reedy and Arnold [8]. Using the incident flux and spectrum of SCR particles and the well-known relations for the slowing down of charged nuclei in matter, this model calculates the fluxes of SCR particles as a function of depth inside a target. These depth-dependent SCR-particle fluxes are calculated well by this approach. The production rate of a nuclide is then calculated by integrating over energy the product of these particle fluxes and the cross sections for the reaction making that nuclide. Often a nuclide can be made in appreciable yield from several different target elements, and this integration must be done for each element. The main limitation of this approach is the need for a detailed excitation function (cross sections as a function of energy) for each important reaction $[8,14]$. Using known excitation functions and satellite-measured fluxes of solar protons, this model has reproduced well the activities of $78-\mathrm{day}{ }^{56} \mathrm{Co}$ measured in several lunar rocks [9]. This type of model has also been applied to several solar-proton-produced nuclides in meteorites by Michel and coworkers [19].

The excitation functicas for the production of long lived ${ }^{26} \mathrm{Al}$ by the reactions of protons with aluminum and silicon arc shown in Fig. 1. Such excitation functions, especially for energies below $100 \mathrm{MeV}$, are nceded for calculating production rates by SCR particles. Because of the rapid decrease in SCR-particle fluxes with increasing energy, the most important cross sections for nuclide production by SCR particles are those ncarest the reaction thresholds. These excitation functions have been fairly well measured (especially by ref. [20]), although llicre are no measured cross sections between 52 and $300 \mathrm{MeV}$ (which is not a serious, problem, as the shape there can be fairly well estimated from other similar excitation functions). There is also a disagrement between the measurements by the Orsny [21, 22] and Bordeaux [2:3, 24] groups for $S i(p, x)^{2 H} A l$ reactions at and abuve $600 \mathrm{MrVV}$, but the uncertainties at such energies only would affect calculations for the production of ${ }^{20} \mathrm{Al}$ by high-energy (ic'R particles. It would $\cdots$ niec to hane several

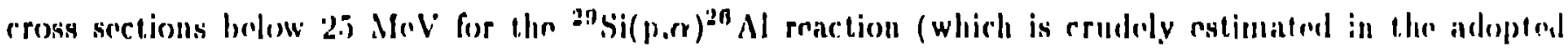
rurve on Fïg. 1).

Production rates ralculated as a function of sample depolh and meteoroid radius for the production of

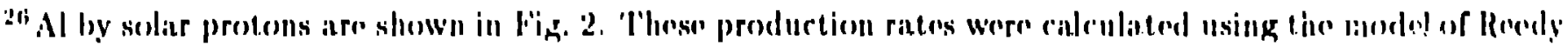


and Arnold [8] after it was modified for spherical meteoroids and with the evaluated excitation functions shown in Fig. 1. The ranges of approximate ${ }^{26} \mathrm{Al}$ GCR production rates are indicated by the $\mathrm{X}$ on the left axis and the "(GCR)" near the right axis and show that solar-proton production of ${ }^{26} \mathrm{Al}$ in meteorites is important in all small meteoroids (radii less than $\sim 15 \mathrm{~g} \mathrm{~cm}^{-2}$ ) and in the outer few centimeters of larger meteoroids. Similar production profiles for ${ }^{26} \mathrm{Al}$ and several other solar-proton-produced radionuclides were reported by ref. [19] for several types of meteorites. For all nuclides made by such low-energy reactions, the production rates drop very rapidly from the surface of the extraterrestrial object, as shown in Fig. 2. The observation of such high concentrations for nuclides made by liw-energy proton-induced reactions is a strong indication that the sample had been very close to the surface. Rates for the SCR production of several nuclides in very small objects (such as indicated by the 0 in Fig. 2) have also be :r. calculated (e.g., $[18,19])$.

Some cosmogenic nuclides can only be made by solar particles with fairly high energies, such as ${ }^{10} \mathrm{Be}$ from oxygen and heavier target elements. Excitation functions for the production of ${ }^{10}$ Be were recently presented in ref. [25], and their proton cross sections at lower snergies are much less than those used previously by Reedy and Arnold [8]. The ${ }^{10}$ Be solar-proton production rates in lunar rock 68815 arc show'n in Fig. 3 for scveral solar-proton spectral shapes and a flux of 70 protons $\mathrm{cm}^{-2} \mathrm{~s}^{-1}$ above $10 \mathrm{MeV}$. The average spectral shape of solar protons for the last few million years have been determined by several groups to be about $R_{o}=100 \mathrm{MV}$, although another group has reported higher values for $R_{0}$ (cf., [1]). The production rate of ${ }^{10} \mathrm{Be}$ in lunar rocks by GCR particles is $\sim 10$ atoms $\mathrm{min}^{-1} \mathrm{~kg}^{-1}$, so solar-protonproduced ${ }^{10} \mathrm{Be}$ at the very surface would be hard to detect unless the precision of the analyses was less than $\sim 10 \%$, especially if the correct solar-proton spectral shape is $R_{0}=100 \mathrm{MV}$ or less. The use of ${ }^{10} \mathrm{Be}$ along with a radionuclide made by low-energy renctions (such as ${ }^{2 \mathrm{~A}} \mathrm{Al}$ or ${ }^{53} \mathrm{Mn}$ ) could be very useful in restricting the possible spectral shapes of the solar proton-. One limitation al present in calculations fre solier-proton-produced ${ }^{10} \mathrm{Br}$ is that there are no measured cross sections for energies below $135 \mathrm{McV}$ (ef., [25]). Some ${ }^{10}$ Be produrtion cross sertions should be measured al several lower proton energies from oxygen and the next most important target group (magnesium, aluminum, and silicon).

Many rross sections used for calculating production rates by solar proton were reportenl in ref. [s], although many are now out of date bersulse of more recent measurements. Mlany exritations functions for targets with atomir numbers from 22 lo 24 have been meisured by Mirhel an 1 coworkers (cf., reforences 
in ref. [19]). Sowever, there is still a need for additional cross sections, such as mentioned above for ${ }^{10} \mathrm{Be}$. Cross sections for the ${ }^{16} \mathrm{O}(\mathrm{p}, 3 \mathrm{p}){ }^{14} \mathrm{C}$ reaction have only been measured once, and some additional cross sections for this and other ${ }^{14} \mathrm{C}$-producing reactioris should be measured to confirm those used in determining the fluxes of solar protons over the last $\sim 10 \mathrm{ka}$ from lunar ${ }^{14} \mathrm{C}$ profiles [14]. The status of other excitation functions for several other solar-proton-produced radionuclides was also reviewed in ref. [14].

The average fluxes of solar protons over several time periods have been determined from measurements of activity-versus-depth profiles of ${ }^{14} \mathrm{C},{ }^{81} \mathrm{Kr},{ }^{26} \mathrm{Al}$, and ${ }^{53} \mathrm{Mn}$ in the top centimeter of lunar rocks. As mentioned above and discussed in refs. [1, 14], there are some disagreements among the measurements. Now that the measurement of some of these long-lived radionuclides by accelerator mass spectrometry (AMS) is well est tblished, it would be a good time to repeat these lunar measurements, especially with a finer depth grid. The inclusion of ${ }^{10} \mathrm{Be}$ with ${ }^{26} \mathrm{Al}$ or ${ }^{53} \mathrm{Mn}$ measured in these samples would help in interpreting the data for the last million years. For example, a different set of spectral shapes and lunarrock erosion rates often could fit the measurements about as well as the adopted values. The average fluxes of solar alpha particles over the last $\sim 100 \mathrm{ka}$ could be studied by the ${ }^{59} \mathrm{Ni}$ made in the top few millimeters of lunar rocks by the ${ }^{56} \mathrm{Fe}(\alpha, \mathrm{n})^{59} \mathrm{Ni}$ reaction. The SCR effects in meteorites should be further studied. especially since the recent discoveries of high concentrations of solar-proton radionuclides in the Salem [16] and ALHA77005 [15] meteorites. As the average fluxes of SCR particles should vary inversely with the square of distance from the sun [1], solar-proton-produced radionuclides could be useful in determining orbits of meteorites.

\section{Galactic cosmic rays}

\subsection{The nature of GCR particles and their interactions}

The major differences between the $S(R$ and $G C R$ are their energies and fluxes. The average energy of a CiC'R proton is $\sim 2$ GeV. and the energies range from a few MeV up to $\sim 10^{20} \mathrm{eV}$. Above $\sim 10$ GeV. the flux of GC'R parifeles decreases with increasing energy roughly as $\mathrm{E}^{-2.65}$. The flux of (C) R particles near the eartle is $\sim 3$ particles $\mathrm{cm}^{-2} \mathrm{~s}^{-1}$. The spectra and lluxes of cic'R particles are modified from those in the local interstellar space by the selar wind and its magnetic field as it expands from the sun. During a typical 11-year solar cycle, the (ic 'R partiele fluxes are the greatest at the time of minimum solar' 
activity and the least at solar maximum. The GCR particles with encrgies below a few GeV nucleon ${ }^{-1}$ are most affected by solar modulation [1], and the integral flux above $1 \mathrm{GeV}$ nucleon ${ }^{-1}$ varies by a factor of 2 between solar minimum and solar maximum [18]. The particles in the GCR are $\sim 8 \pi \%$ protons, $\sim 12 \%$, alpha particles, and $\sim 1 \%$ heavier nuclei [26].

As the ranges of $\mathrm{GCR}$ protons and alpha particles are much longer than their interaction lengths, almost all GCR particles induce nuclear reactions before they are stopped in matter. These high-energy reactions usually result in many secondary particles, especially pions and neutrons. On average, each GCR particle makes $\sim 7$ neutrons $[8,11]$ in its cascade of particles. Most of the secondary charged particles in this cascade are stopped by ionization energy losses, but the neutrons travel until they scatter from or react with a nucleus or they escape from the object. Below $\sim 100 \mathrm{MeV}$, the dominant particles in the GCR cascade in all but the smallest objects are neutrons [8, 12]. The fluxes of GCR particles with energies above $1 \mathrm{GeV}^{\prime}$ nucleon ${ }^{-1}$ decrease exponentially in a large object, while the fluxes of the secondary neutrons first build up then decrease exponentially with depth [8].

Because the types of the particles and their energies in this cascade are sensitive to the size of the object and the deyth inside it, the production rate of a cosmogenic nuclide can vary considerably in extraterrestrial matter. This effect of depth, size, and shape on production rates is referred to as "shielding." In predicting the production rate of a nuclide by GCR particles, shielding needs to be considered along with the chemical composition of the sample. The effects of shielding vary considerably with the types of reactions that produce a cosmogenic nuclide, with the extremes being nuclides made only by highenergy reactions (e.g., ${ }^{10} \mathrm{Be}$ ) and those made by neutron-capture reactions (such as ${ }^{59} \mathrm{Ni}$ and ${ }^{60} \mathrm{Co}$ in large objects). The production-rates-versus-depth profiles shown in Fig. 4 for the moon illustrate these two extremes and two intermediate cases for the variation of shielding effects with the nature of the nuclear reactions producing a cosmogenic nuclide.

\subsection{Different approaches to predicting production rates by GCR particles}

Unlike the case for SCR particles, where only a couple of approaches have been used to predict the production rates of cosmogenic nuclides, there have been many different methods used for predicting GCR-particle interactions in extraterrestrial matter. This large number of approaches is partially berause CiCR-produced nuclides have been studied for about twice as long as SCR-produced uclides but is mainly due to the variety of extraterestrial material in which GCR-produced nuclides have been studied (stony 
meteorites, iron meteorites, lunar samples, and cosmic spherules) and the diversity in types and energies of GCR particles inside these objects. Four approaches will be discussed in more detail in sections below: use of cosmogenic-nuclide systematics measured in extraterrestrial samples, theoretical calculations, models using inforred particle spectra and reaction cross sections, and laboratory simulation irradiations. Several other approaches will be briefly described in the next two paragraphs. These various approaches have their advantages and their limitations. Most models have fairly well reproduced the measured concentrations and profiles for cosmogenic nuclides in extraterrestrial matter.

One of the simpler approaches to predicting production rates has been to detern.ine the prcduction ratio of two cosmogenic nuclides and to get the rate for haking one of these nuclides from this ratio and a known rate for the other nuclide. Cor many nuclides made by high-energy reactions (e.g., ${ }^{36} \mathrm{Cl},{ }^{37} \mathrm{Ar}$, and ${ }^{39} \mathrm{Ar}$ in the metal phases of meteorites), the cross section ratios measured at an accelerator with $\mathrm{GeV}$ protons can be used to predict production ratios. The cross sections for the production of most nuclides made by high-energy spallation reactions systematically vary with $\Delta A$, the difference in the mass of the target to that of the product. For $\Delta A>5$, the yield of all species with mass $A, Y(A)$, can be expressed

$$
Y(A)=c(\Delta A)^{-k}
$$

where the power $k$ typically varies between 2 and 3 for GCR-particle react:ons in iron meteorites [3]. To get the relative rate for a specific isotope, the isobaric yield of that isotope for that mass needs to be known [3]. This expression does not work well for products very close in mass to the target or with masses below about 15 (e.g., ${ }^{10} \mathrm{Be}$ ).

One of the oldest models is that used by Signer and Nier [4] to parameterize their measurements for the distribution of noble-gas isotopes in large pieces of iron meteorites. This model uses an equation that considers only the exponential decay of primary GCR particles and the growth and subsequent exponential decay of secondaries along the path of the incident primary particle. This equation can be integrated for simple geometries. This approach does not consider energy losses or wide-angle production or scattering of the particles. This model works best for cosmogenic nuclides made by high-energy reactions, such as most nuclides in iron meteorites, where the model's limitations are least important. It has recently been applied to ${ }^{10}$ Be and noble-gas isotopes in the knyahinya chondrite [27]. 


\subsection{Systematic measurements of nuclides in extraterrestrial samples}

Soon after the discovery of cosmegenic nuclides in meteorites in the early 1950s, some systematic studies were done [2]. Several cosmogenic nuclides were measured in samples from a iarge number of meteorites. These studies showed that, to a first approximation, the production rates of most cosmogenic radionuclides did not vary considerably in most mateoritic samples. For example, the spread in activities of cosmogenic radionuclides was typically within $\sim 20 \%$ of the mean activity. Several isotopic ratios were shown to correlate well with other ratios, such as the ${ }^{22} \mathrm{Ne} /{ }^{21} \mathrm{Ne}$ ratio versus the ${ }^{3} \mathrm{He} /{ }^{21} \mathrm{Ne}$ ratio. More recently, experimental trends of meteoritic measurements (e.g., [28]) showed that the ${ }^{22} \mathrm{Ne} /{ }^{21} \mathrm{Ne}$ ratio was a fairly good indicator of shielding for several radionuclides.

Some additional studies concentrated only on a number of samples from known locations of one meteorite, such as cores from the Keyes, Jilin, and St. Severin chondrites (e.g., [25]) or slabs from several iron meteorites (for example, [4]) and the Knyahinya chondrite [27]. These measurements for chondrites showed that the activity of a radionuclide as a function of depth in most meteorites increased with increasing depth near the surface, then remained fairly constant in the central parts. Iron meteorites, which are usually much larger than stony meteorites, have production profiles that often decrease towards the center (e.g., [4]). The trend lines, such as a radionuclide activity versus the ${ }^{22} \mathrm{Ne} /{ }^{21} \mathrm{Ne}$ ratio, for these cores or slabs sometimes have different slopes than did the same trend line for samples from different meteorites. Several studies used samples with different chemical compositions from one meteorite (such as mineral separates) or a group of meteorites to determine production rates from individual target elements, such as rates for producing ${ }^{26} \mathrm{Al}$ from aluminum, silicon, and other elements.

Many of the results from these systematic studies, such as the trend lines, have been used in predicting production rates in metcorites. These measurements also have been valuable in developing and testing models for the production rates of cosmogenic nuclides (e.g., $[4,12])$. Often the calculated production rates for a nuclide from such models should be normalized to experimentally determined production rates. Additional systematic studies are being done, especially for long-lived radionuclides that have only recently been made easier to analyze by AIS. Some detailed studies of many cosmogenic nuclides in several samples from a meteorite also are being done, especially for meteorites with a wide range of preatmospheric sizes (e.g., [29]). 


\subsection{Theoretical caiculations}

The production rates for several cosmogenic nuclides have been calculated by computer codes that use only some basic nuclear data, such as scattering, capture, and reaction cross sections, and are not normalized to observations. As discussed abcve in the section on SCR calculations, Monte Carlo calculations have teen done for cosmogenic nuclides in lunar samples by Armstrong and Alsmiller [10]. For the GCR, they published production-rate-versus-depth profiles for ${ }^{26} \mathrm{Al}$ and ${ }^{22} \mathrm{Na}$ and the neutron fluxes as a function of depth. The calculations followed the neutrons until they reached thermal (technically $<0.4 \mathrm{eV}$ ) energies. The calculated ${ }^{26} \mathrm{Al}$ and ${ }^{22} \mathrm{Na}$ production rates and the thermal-neutron fluxes were consistent with lunar measurements [10]. As with the SCR Monte Carlo calculations, these Gr R calculations [10] show the basic processes involved but are of limited use in detailed studies of cosmogenic nuclides in lunar samples.

The one case where essentially pure thenretical calculations have been very useful in studies of cos. mogenic nuclides is for nuclide production by the capture of neutrons with low (thermal and epithermal) energies. The radionuclides that can be made in appreciable amounts by neutron-capture reactions include 5.7 -year ${ }^{60} \mathrm{Co}, 75-\mathrm{ka}{ }^{59} \mathrm{Ni}, 100-\mathrm{ka}{ }^{41} \mathrm{Ca}$, and (orcasionally) $300-\mathrm{ka}{ }^{36} \mathrm{Cl}$. Several results for such neutron-transport calculations have been published for the moon $[10,11]$ and meteorites (e.g., [30]). These calculations start with the chemical composition and the corresponding nuclear properties of the object and with the fluxes of energetic $(\sim 1-10 \mathrm{MeV})$ ncutrons made in the GCR-particle cascade as a function of energy and depth. The equilibrium distribution of neutrons is then calculated. The production profile in Fig. 4 for ${ }^{60} \mathrm{Co}$ in the moon was calculated by a neutron-transport code [11]. Although ${ }^{36} \mathrm{Cl}$ is usually produced in much greater quantities by spallation reactions than by neutron-capture reactions [30], the latter source can be important in big objects with samples having high chlorine contents, as was the rase for the Apollo 15 drill core [31].

As shown in Fig. 1, the production-rate-versus-depth profiles for neutron-capture products are very different than those for nuclides made by higher-energy reactions, being very low at the surface and peaking with much higher production rates at fairly great depths. In meteorites. production of nuclides by thermal neutrons is negligible until the preatmospheric radius is greater that $\sim 75 \mathrm{~g}^{\mathrm{cm}} \mathrm{cm}^{-2}$, and the presence of neutron-capture-produced nuclides means that the meteorite was large in space [30]. These big changes in the production rates of neutron-capture-produced nuclides allow us to sometimes use such nuclides to infer a sample's preatmospheric depth. Unfortunatedy, neutron-capturoproduced nuclicles have seldom boen 
used in meteorite studies, mainly because the relatively sinort half-life of readily measurable ${ }^{60} \mathrm{Co}$ and the weak radiations emitted by the decay of long-lived ${ }^{59} \mathrm{Ni}$ and ${ }^{41} \mathrm{Ca}$. If AMS techniques can be developed for the low ratios of these long-lived radionuclides to the stable isotopes of the same element, then these products with their very different production profiles could be used to help unfold the exposure histories of meteorites.

\subsection{Inferred particle fluxes and reaction cross sections}

This approach to calculating production rates is similar to the main one used for SCR-produced nuclides, except that the particle fluxes are not calculated by a simple relaticn like ionization energy loss but must be infersed by other m sans. When Arnold, Honda, and Lal [5] used this approach in predicting the production rates of cosmogenic nuclides in iron metcorites, they used particle fluxes derived from several sources. For the primary RCR particles, they used available expcrimental data. For secondary particles above $100 \mathrm{MeV}$, they used data îrom nuclear emulsions that had been exposed at high altitude and other measurements in the eaith's atmosphere. The flux as a function of energy used for all particies with energies above $100 \mathrm{MeV}$ was

$$
\frac{d J}{d E}=c(\alpha+E)^{-2.5}
$$

where $\alpha$ was $1.0,0.4$, and $0.2 \mathrm{GcV}$ for the primary GCR particles and for depths of 10 and $100 \mathrm{~g} \mathrm{~cm}^{-2}$, respectively, and $c$ was normalized to experimental cosmic-ray fluxes above $3 \mathrm{GeV}$. Below $100 \mathrm{MeV}$, they considered only neutrons and used a spectrum based on measurements made in the earth's atmosphere. This spectrum was normalized to agree with (3) at $100 \mathrm{MeV}$. The cross sections above $100 \mathrm{MeV}$ were based un spallation systematics. The cross sections below $100 \mathrm{MeV}$ assumed that the incident particle was a neutron. Experimental cross sections were used whenever possible. The production rates were calculated by integrating over energy the product of the fluxes and cross sections and generally reproduced the trends for cosmogenic nuclides incasured in the Aroos iron meteorite [5].

The same approach was used by Reedy and Arnold $[y]$ for the moon, and they used many of the features of the above model. The main differences were that the flux above $100 \mathrm{MeV}$, (3), was allowed to continuously vary with depth in the moon, and the flux shape below $100 \mathrm{MeV}$ was made a function of ar. The Reedy-Arnold spectral shape bolow $100 \mathrm{M} \times \mathrm{V}$ was based on the one from ref. [5] for deep in the moon and on activities of cosmogenie muclides in lunar samples a. : theoretical calculations [10] for near the lunar 
surface. The GCR-particle fluxes above $1 \mathrm{GeV}$ as a function of depth in the moon were calculated from known interaction lengths and parameters for the incident GCR protons and alpha particles. This model thus has only one free parameter, $\alpha$, and a curve for $\alpha$ versus depth was derived from several sources. Many excitation functions were constructed using experimental cross sections or estimations based on nuclear systematics. This model only considers particles with energies down to $\sim 1 \mathrm{MeV}$ and can not be used for calculating neutron-capture rates. It has reproduced the activity-versus-depth profiles measured in lunar samples quite well, although occasionally absolute values are off by up to $\sim 40 \%$, such as for ${ }^{53} \mathrm{Mn}$. It is believed that these few poorly calculated absolute production rates are a consequence of using incorrect cross sections, especially using proton-induced ones at energies below $\sim 100 \mathrm{MeV}$ where neutron-induced cross sections should be used.

The flexibility of this approach has been illustrated by the fact that new production rates are frequently being calculated using new cross sections. Beside the problems with the lack of cross sections for neutroninduced reactions, the only other deficiency has been the nudel's failure below depths of $\sim 350 \mathrm{~g} \mathrm{~cm}^{-2}$. Down to that depth (few lunar cores go much deeper), the Reedy-Arnold model [8] has worked quite well, especially if good measurements can be found to normalize the calculated production profiles at one depth. The aviliability of new cross sections have almost always resulted in better agreement between the calculated production rates and ineasurements of cosmogenic nuclides in lunar samples and meteorites (for example, ${ }^{10} \mathrm{Lo}$ in St. Severin [25]). There are still many reactions for which experimental cross sections are needed, both for protons with energies above $\sim 100 \mathrm{MeV}$ and for neutrons at lower energies. The model has been surprising successful even though it oaly has one free parameter, $\alpha$.

The Reedy-Arnold model was extended to metcorites by ref. [12]. Curves for $\alpha$ as a function of depth were derived for two meicorites with different preatmospherie radii (St. Severin and Jilin), and an expression was devoloped that could calculaled $\alpha$ for any radius and depth [12]. The ${ }^{20} \mathrm{Al}$ production rates shown in Fig. 5 for l, chonctrites were calculated with this model The model fails for very large (radii more than, $200 \mathrm{~g} \mathrm{~cm}^{-2}$ ) meternites, most likely because the derivation ci a for such radii was not

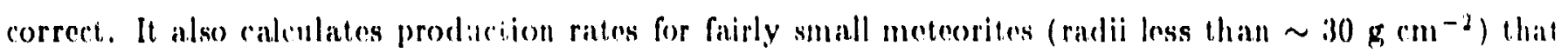
are too high, probably berause the model hits too many neutrons for such small objerts. An improved model for fairly small meterites will probably need to consider protons and neutrons separatcly, as the Hux of nentrons increases fast with ratius in such small bodies. As mentioned above, this modnd does work 
well for very small objects, such as those that possibly are the parent bodies for cosmic spherules [17], because secondary-particle fluxes are negligible and only the well-known primary-GCR-particle fluxes and proton-induced cross sections are needed [18].

\subsection{Simulation irradiations at accelerators}

Many thick targets have been irradiated with high-energy particles at accelerators to simulate the cosmic-ray bombardment of extraterrestrial matter (see review of thick target experiments in ref. [2]). In these irradiations the distributions of various products are measured at several locations inside the target. These product distributions varied with the nature of the reactions producing them. For example, in Honda's bombardment of a thick iron target with 3-GeV protons [6], the activities of high-energy products, like ${ }^{22} \mathrm{Na}$, decrease rapidly with depth and had very little !ateral spread, whereas radionuclides made hy low-energy reactions, such as ${ }^{55} \mathrm{Fe}$, btilt up at first with depth and the lateral spread was broad. These radioactivities map the distributions of the primary and secondary cosmic-ray particles in large objects in space. Honda developed relations to convert these thick-target tieasurements into production profiles expected in iron meteorites. A more detailed set of expressions was developed by hohman and Bender [7] for converting thick-target results into production profiles in iron meteorites. Their production profiles for fairly low energy reactions look similar to that for ${ }^{26} \mathrm{Al}$ in Fig. 5 . The production rates from these models for high-energy products show very little increase near the surface (:nmewhat like tho ${ }^{10}$ Be curve in Fig. 4).

The production profiles inferred from thick-target irradiations were among the first predicted for meteorites and are still useful in interpreting cosmogenic-nuclide mea.urements. However, they are limited to nuclides that have been measured in the bombarded thick targets or for other nuclides made by similar reactions (such as using ${ }^{54} \mathrm{Mn}$ to model production of ${ }^{33} \mathrm{Mn}$ ). Most thick targets were iron, and only a few groups irradiated stony targets (see compilation of thick-target experiments in ref. (2)). Some of the production profiles from these thick-target models are not very good, such as these for large stony objects reported by ref. [32] (as discussed by ref. [30]). Some of the targets were too small fo contain the entire ascade of secondary particles, and thus the particle distribution inside the target was distorterl [33]. Almost all of these thick-target bembardments used high-energy protons [2]: however, $212 \%$ of the particles in the (ic:R aro alpha particles [26)], which interact differently in thick targets [3:3]. As with most 
results obtained prior to AMS, certain long-lived radionuclices, for example ${ }^{10} \mathrm{Be}$, were seldom measured in these thick-target experiments.

Another limitation of most thick-target experiments is that they are not applicable to fairly small objects. The full cascade of secondary particles usually is generated in a thick target, but only the initial stages of such cascades will have developed in small objects. Thus the models like that of Kchman and Bender [7] are probably not valid for such small objects. Recently, several isotopic irradiations with

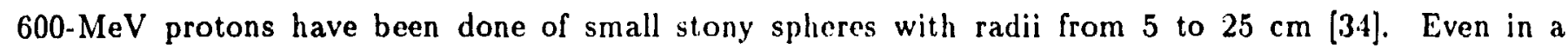
sphere of radius $5 \mathrm{~cm}$, there are a number of secondary neutrons, and the neasurements are in fairly good agreement with Monte Carlo calculations [34]. Additional isotropic irradiations of small "thick targets" are being planned, including spheres with several different chemical compositions and possibly of an ellipsoidal target.

\section{Summary and conclusions}

As surveyed above, there are many methods used to predict the production rates of cosmogenic nurlides by cosmic-ray particles in extraterrestrial matter. All models have their strengths and their weaknesses. Most approaches work well, although the agreement with experimental measurements of cosmogenic nuclides in real samples is the ultimate test of any model. Only a very few models aue so theoretical that they don't need the results of measurements of naturally or artificially irradiated samples. 'These measurements, especially of the long-lived radionuclides now being readily measured by AMS, are very important in improving our predictions of production rates. As additional radionuclides, such as $"$ ( a and ${ }^{39} \mathrm{Ni}$, become moasurable by $\mathrm{AMS}$, studies of those nuclides in both artificially irradiated targets and in extratererstrial materials will be needed to help in predicting their production rates. Some of the methods and data used for extraterestrial samples can be applied to cosmogenic racionuclides made in the earth's atmosphere and surface. For example, cross sections for the production of nuclides like ${ }^{20} \mathrm{Al}$ and "Be can be used with fluxes of terrestrial neutrons to calculated production rates.

for the anclides matdo by the protons and alpha particles in the selar cosmic rays, the mest important

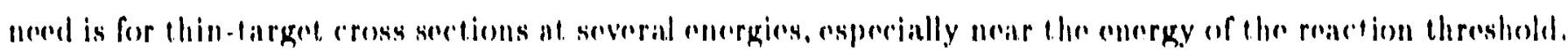

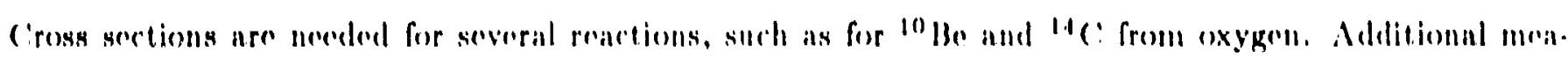
surements of longe-lived radionucideles in lunar samples also shembld be dome to confirm and extend existing studies of the iluxes of SC'R particlene in the past (1.1). Very little work has beren done on the fluxen of solint 
alpha particles in the past using ${ }^{59} \mathrm{Ni}$ in the top few millimeters of lunar samples. Such studies probably would be one of the first projects to do when the AMS techniques for $\mathrm{Ni}$ are fairly well established because the nickel contents of lunar samples are low, so the ${ }^{59} \mathrm{Ni} / \mathrm{stable}-\mathrm{Ni}$ ratios wnn't be too low.

For nuclides produced by the galactic cosmic rays, many typ ?s of measurements are needed. Systematic studies of cosmogenic-nuclide concentrations in extraterrestrial samples are important in predicting production rates. Most models need such measurements to determine their parameters or for normalizations of the absolute activities. Many cross sections are needed for the production of these nuclides by energetic protons and especially neutrons with energies up to $\sim 100 \mathrm{MeV}$ (and more in several cases, such as $\left.{ }^{10} \mathrm{Be}[25]\right)$. Laboratory simulations using thick targets or isotropically irradiated targets, especially for long-lived Iadionuclides, are still valuable in helping to predict production rates. These simulations are useful in testing Monte Carlo calculations, such as was done for the $5-\mathrm{cm}$ sphere [34]. These Monte Cario calculations, such as those with the High Encrgy Transport Code used by ref. [34], are being improved, and soon incident high-energy alpha particles will be included in such calculations.

$\Lambda$ wide range of problems can be studied with these predicted production rates and measurements of long-lived cosmogenic radionuclides in extraterrestrial samples. The lengths of time that the thousands of meteorites now being found in Antarctica have been on or in the ice, their terrestrial ages, are important for many studies of these interesiing and often unique (for example, those from the moon) meteorites. Better exposure ages are needed to help determine the origin of meteorites. Especially important will be the ability to distinguish between simple irracliation histories and those complex irradiations that wecured both before and after the meteorite was broken apart in space by a collision. Such studies of the irradiation histories of meteorites will help to determine where the parent bodies were in the solar system. More studies of the cosmic spherules found in deep-sen sediments [1i] will help to determine the origins of these interesting objects, such as wherther they were small objects in space or are just fragments of larger meteorites that broke apart whike passing throngh the aarth's atmosphere. Some meteorites or cosmic spherules may have had unusual orbits around the sun, such as small periholions or high inclinations (a region of the solar system that has not brom explore yet by satellitess).

Gne gront power of AMSS is its ability Le measure the concentrations of long lived radionuclides in small samples, which allows us to measure snany different cosmogenir nuclides in a sample. The more nuclidess and other cosmir-ray products (such an eracks of heavy cosmic- ray nucloi) measured, the hetter our ability 
to interprat all aspects of the sample's history [1]. For example, short-lived radionuclides can establish the production rates if the object had a short or complex irradiation history. Radionuclides like ${ }^{81} \mathrm{Kr}$, ${ }^{36} \mathrm{Cl}$, and ${ }^{26} \mathrm{Al}$ can be used to determine terrestrial ages of Antarctic meteorites. Long-lived radionuclides can occasionally show that the object had an unusual exposure history. Extending the range of half-lives available, such as with $16-\mathrm{Ma}{ }^{129} \mathrm{I}, 32-\mathrm{Ma}{ }^{92 g} \mathrm{Nb}$, or $103-\mathrm{Ma}{ }^{146} \mathrm{Sm}$, would be very useful in studies of most extraterrestrial materials, as these half-lives are similar to many exposure ages. Much of the more exciting work that will be done during the next fow years with extraterrestrial materials will involve measurements of long-lived radionuclides done with AMS.

\section{Acknowledgements}

This paper benefited from nearly countless past collaborations and discussions with many of my colleagues, especially Peter Englert, Jim Arnold, D. Lal, David Elmore, and Kuni Nishiizumi. This work was supported by NASA purchase urder T-29.4M and done under the auspices of the U.S. Department of Energy.

\section{References}

[1] R.C: icedy, J.R. Arnold, and D. I,al, Annu. Rcv. Nucl. Part. Sci. 33 (1983) 505.

[2i R.C. Reedy and P. Englert, Werkshop on Cosmogenic Nuclides (Lunar and Planetary Institute, Houston, Tech. Rpt. 86-(n6, 1986) $80 \mathrm{pp}$.

[3] M. Ionda and J.R. Arnold, Scirnec 143 (196.1) 203.

[1] P. Signer and A.?. Nirr, J. Ciropilys. Res. $60(1960) 29.17$.

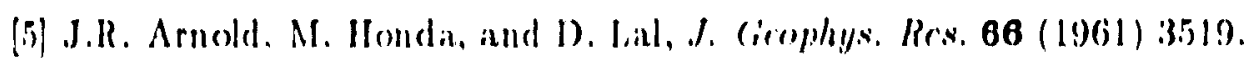

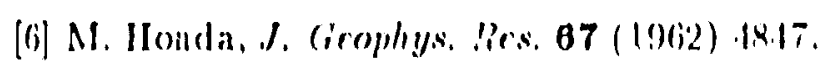

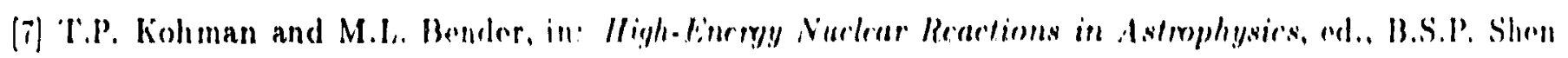
(Benjamin, New York, 196i) 1). 169. 
[8] R.C. Reedy and J.R. Arnold, J. Geophys. Res, 77 (1972) 537.

[0] R.C. Reedy, in: Procecdings of the Eighth Lunar Science Conference (Pergamon, New York, 197i) p. 825 .

[10] T.W. Arrnstrong and R.G. .slsmiller, Jr., in: Prorcedings of the Second Lunar Science Conference (MIT Press, Cambridge, Mass., 1971) p. 1729.

[11] R.E. Lingenfelter, E.II. Canfield, and V.E. Hampel, Earth '?lanet. Sci. Lett. 16 (1972) 355.

[12] R.C. Reedy, J. Geophys. Res. 90 (1985) C722.

[13] R.E. McGuire, T.T. von Rosenvinge, and F.B. M.Donal.1, Astrophys. J. 301 (1986) 938.

[14] R.C. Reedy, in: The Ancient Sun: Fossil Rerort in the Earth, Moon, and Metiorites, eds., R.O. Pepin, J.A. Eddy, and R.B. Merrill (Pergamon, Now York, 1980) p. 365.

[15] K. Nishizumi, J.R. Arnold, J.N. Coswami, J. Klcin, and R. Middleton, Metcoritirs 21 (1986) 172.

[16] J.C. Evans, J.II. Reeves, and R.('. Reedy, Lanar Planet. Sci. 18 (198i) 271.

[17] (i.M. Raisbeck, F. Yiou, J. Klein, R. Middleton, Y. Yamakoshi, and D.E. Brownlee, Lunur Plarct. Sci. $14(198: 3) 622$.

[18] R.C. Reedy, J. Goophys. Ros, 92 (1987) E697.

[19] R. Michel, (i. Brinkmann, and R. Stïck, Earth Plunet. Sri. Lett. 59 (1982) 33, plus erratum in ibid. $64(198: 3) 17.4$.

[20] M. Furukawa, K. Sinizuri, K. Komura, K. Sakamoto, and S. Tanaka, Null. Phys. A174 (1971) 5i3!).

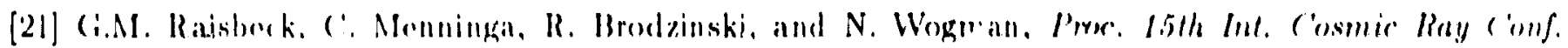
(Povidiv) $2(197 i) 116$.

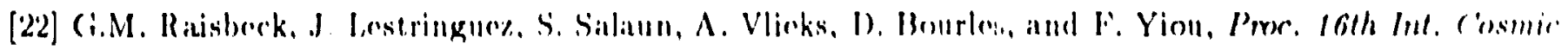
Rny Conf. (kyoto) 2 (1979) 20)i. 
[23] S. Regnier, M. Lagarde. G.N. Sirnonof, and Y. Yoknyama, Earth Planet. Sri. Lelt. 18 (1973) 9.

[24] .I. Dedieu, Thesis, Univ. Bordeaux I (1979) 76 pp.

[25] C. Tuniz, C.M. Smith, R.K. Moniot, T.II. Kruse, W. Savin, D.K. Pal, G.F. Herzog, and R.C. Reedy, Geochim. Cosmocinim. Acta 48 (1984) 1867.

[26] J.A. Simpson, Annu. Bcv. Nucl. Part. Sci. 33 (1983) 323.

[27] Th. Graf, P. Signer, and K. Wieler, Metecritics 21 (1986) 376.

[28] K. Nishiizumi, S. R ggnier, and K. Marti, Earth lanct. Sci. Lett. 50 (1980) 156.

[29] P. Enğlert, U. Herpers, R. Sarafin, J.T. Padia, and M.N. Rao, üct:shim. Cosmochim. Acta 5c (i986) 1.593.

[30] M.S. Spergel, R.C. Reedy, O.W. Lazareth, P.W. Levy, and L.A. Slatest, J. Geo!hys. Res. $\theta 1$ (1936) D.183.

[31j K. Mishiizumi, D. Elmore, X.\%. Mia, and J.R. Arnold, Earth :'lanet. Sri. Lelt. 70 (198.4) L57.

[32] B.M.P. 'Trivedi and P.S. Coel, J. Geopliys. Res. 78 (!973) 4385.

[3:] [P. Enghert, R.C. Rrady, ard J.R. Arnotd, Nuci. Instr. and Weth., subrnittec:

[3.1] R. Michel, P. Dragovitsch, P. Fuglert, F. Peiffer, R. Stück, S. Theis, F. Begemann, Il. Weber, P. Signct. R. Wieler, D, liilges, and P. ('loth, Nurl. Instr. and M/eth. B16 (1986) 61.

\section{Figure captions}

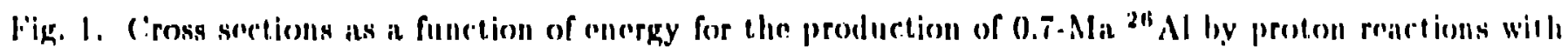

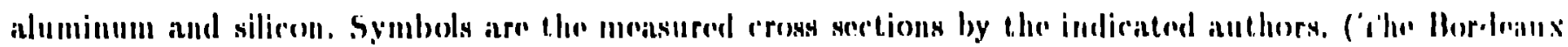

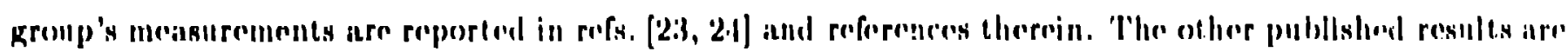

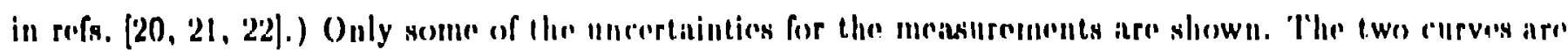

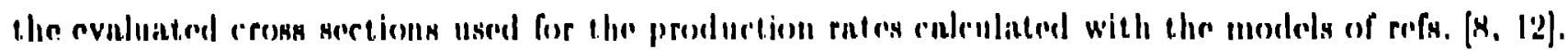


Fig. '2. The rates calculated for the solar-proton production of $0.7-\mathrm{Ma}{ }^{25} \mathrm{Al}$ as a function of preatmospheric depth inside spherical meteoroids of various radii. A solar-proton spectrum with $R_{o}=100 \mathrm{MV}$ and a flux above $10 \mathrm{MeV}$ of 70 protons $\mathrm{cm}^{-2} \mathrm{~s}^{-1}$ were used. The chemical composition was that of an $\mathrm{L}$ chondrite. The symbols $\mathbf{O}$ and $\mathrm{X}$ on the left axis are the production rates calculated for a very small object of this composition by solar protons and GCR protons, respectively. The symbol (GCR) is the GCR production rate of ${ }^{26} \mathrm{Al}$ observed irside typica! L, chondrites, which have radii greater than $\sim 40 \mathrm{~g} \mathrm{~cm}^{-2}$.

Fig. 3. The rates calculated for the solar-proton production of $1.6-\mathrm{Ma}{ }^{10} \mathrm{Be}$ as a function of depth in lunar rock 68815 for several exponential-rigicity spectral shapes. For all spectral shapas. the omnidirectional flux above $\mathrm{M} \in \mathrm{V}$ was 70 protons $\mathrm{cm}^{-3} \mathrm{~s}^{-1}$. Also shown are the ${ }^{10} \mathrm{Be}$ production rates of ref. [8] calculated usir.g an earlier set of cross sections; they are a factor of 2 higher than the present calculated production rates done with the ${ }^{10}$ ie production cross sertions given in ref. [25]. Only very hard spectra (high values of $R_{0}$ ) yield signifirant amounts of ${ }^{12} \mathrm{Be}$ ccinpared to the $\sim 10$ atoms $\mathrm{min}^{-1} \mathrm{~kg}^{-1} \mathrm{produced}$ by GCR particles at these depths.

Fig. 4. The sates calculated for the Cica productio: of four radionuclides as a function of depth in the moon. These produc:ion profiles are examples for cosmogenic nuclides made mainly by high-energy reactiois $\left({ }^{10} \mathrm{Be}\right)$, both low- and high-eicrgy reactions $\left({ }^{26} \mathrm{Al}\right)$, low-energy $(\sim 10 \mathrm{MeV})$ neutron reactions $\left({ }^{39} \mathrm{Ar}\right)$, and by the capture of thermal neutrons $\left({ }^{60} \mathrm{Co}\right)$.

Fig. 5. The rates calculated for the (iCR production of $0.7-\mathrm{Ma}^{26} \mathrm{Al}$ as a function of preat mospheric ciepth inside spherical metcoroids of various radii [12]. 'The chemical composition was that of an $L$ chondrite. The symbol $X$ on the left axis is the production rate calculated for a very smail object of this composition by riciR protons $[14]$. 


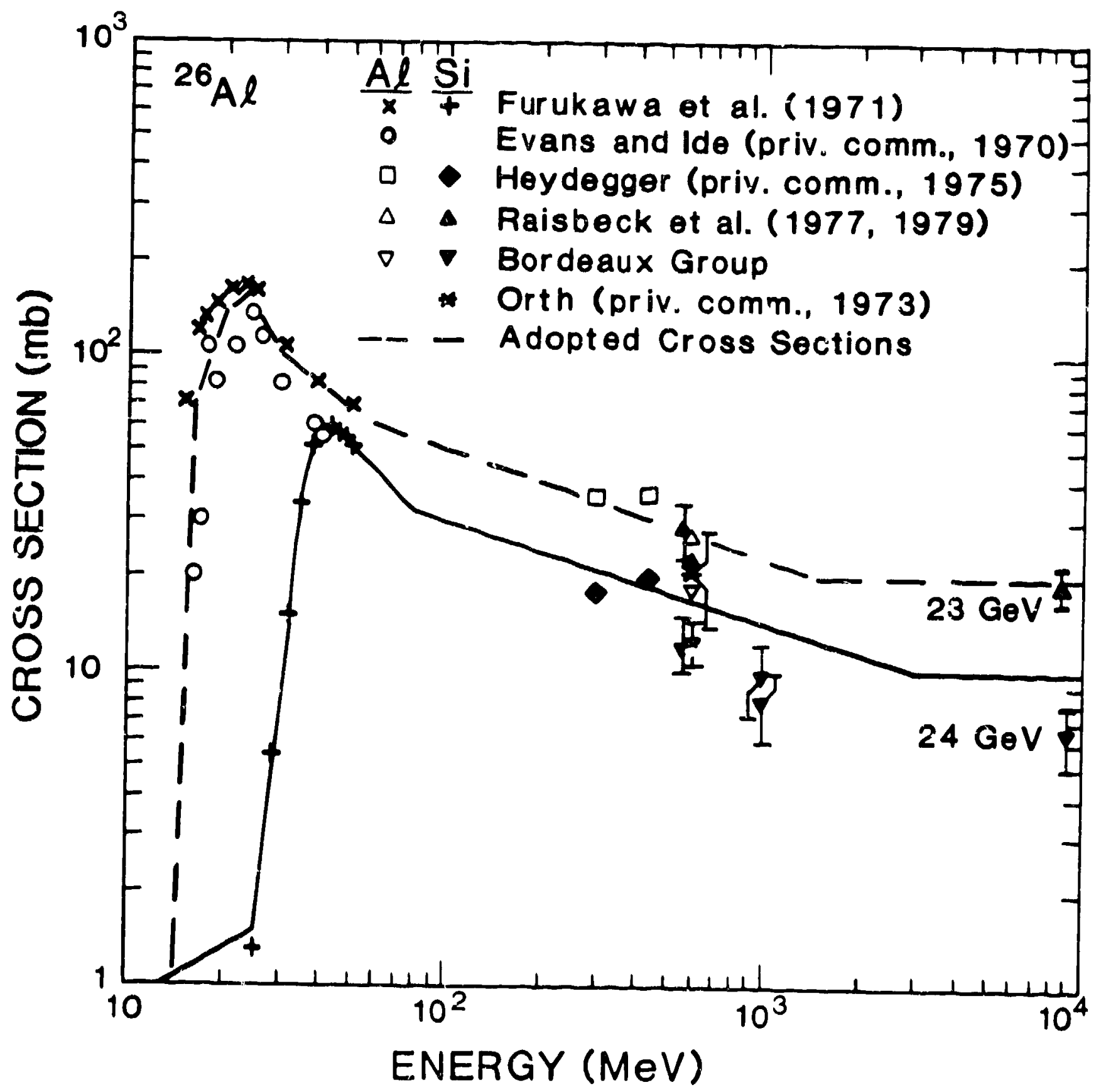

Fig. 1 


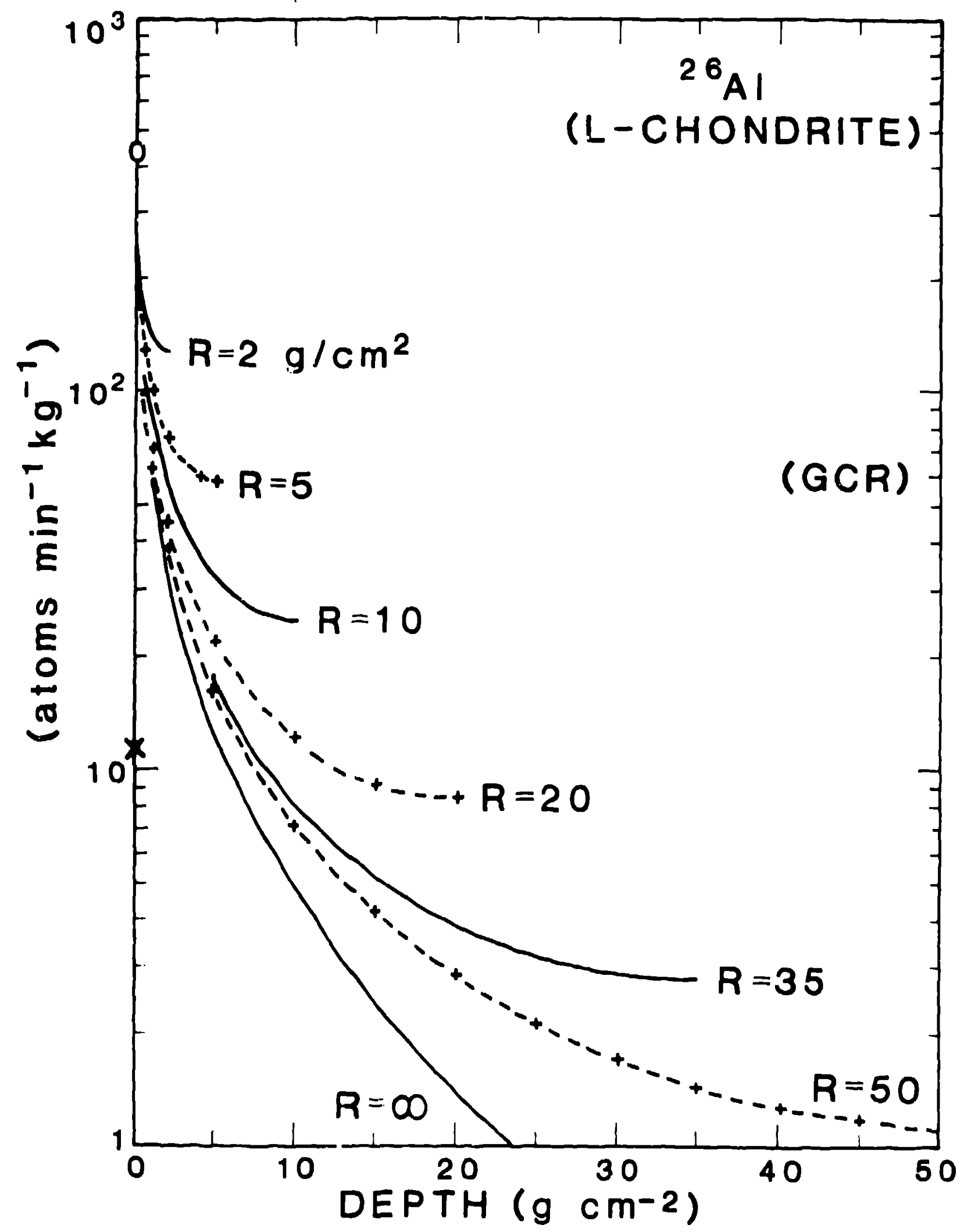

Fig. 2 


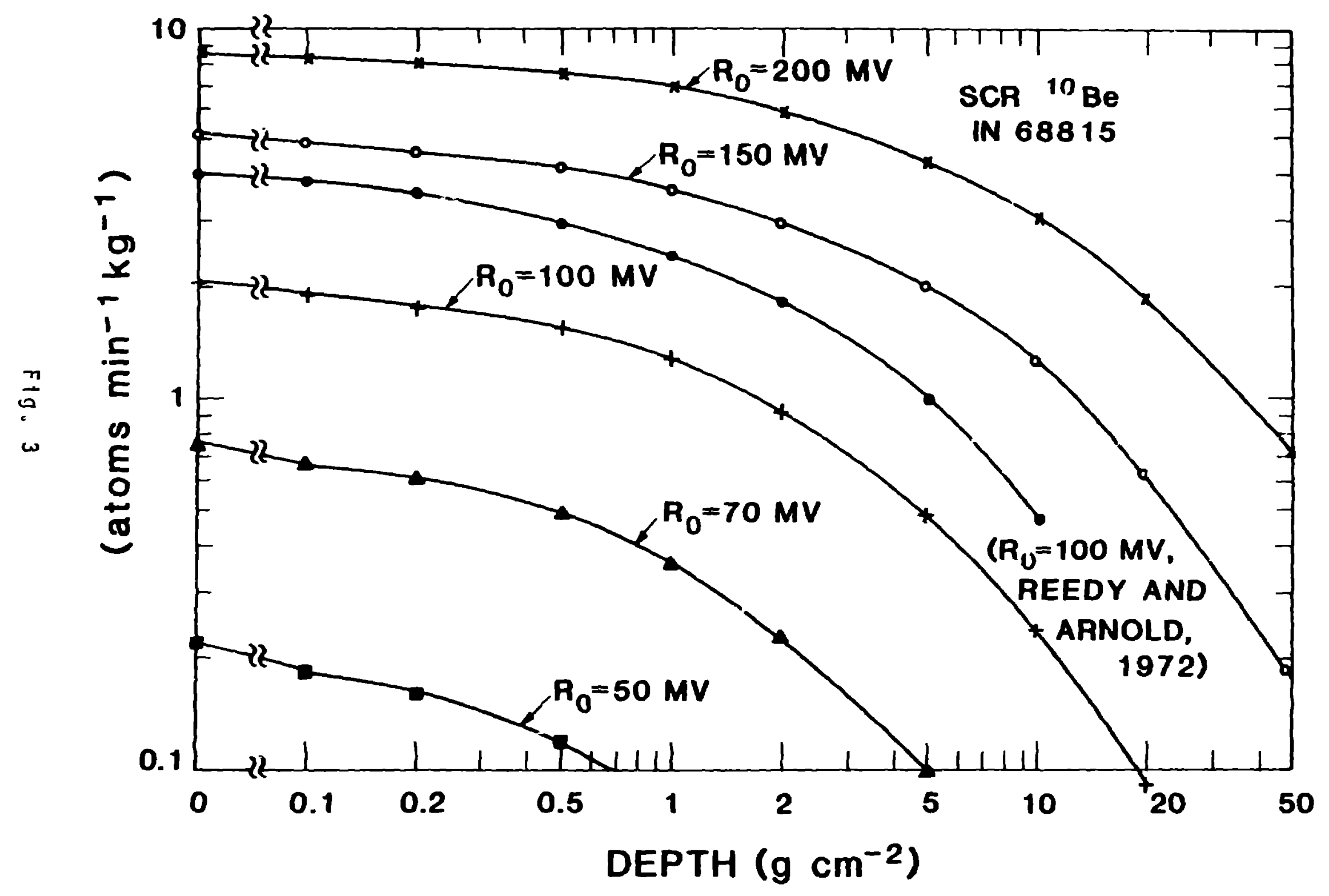




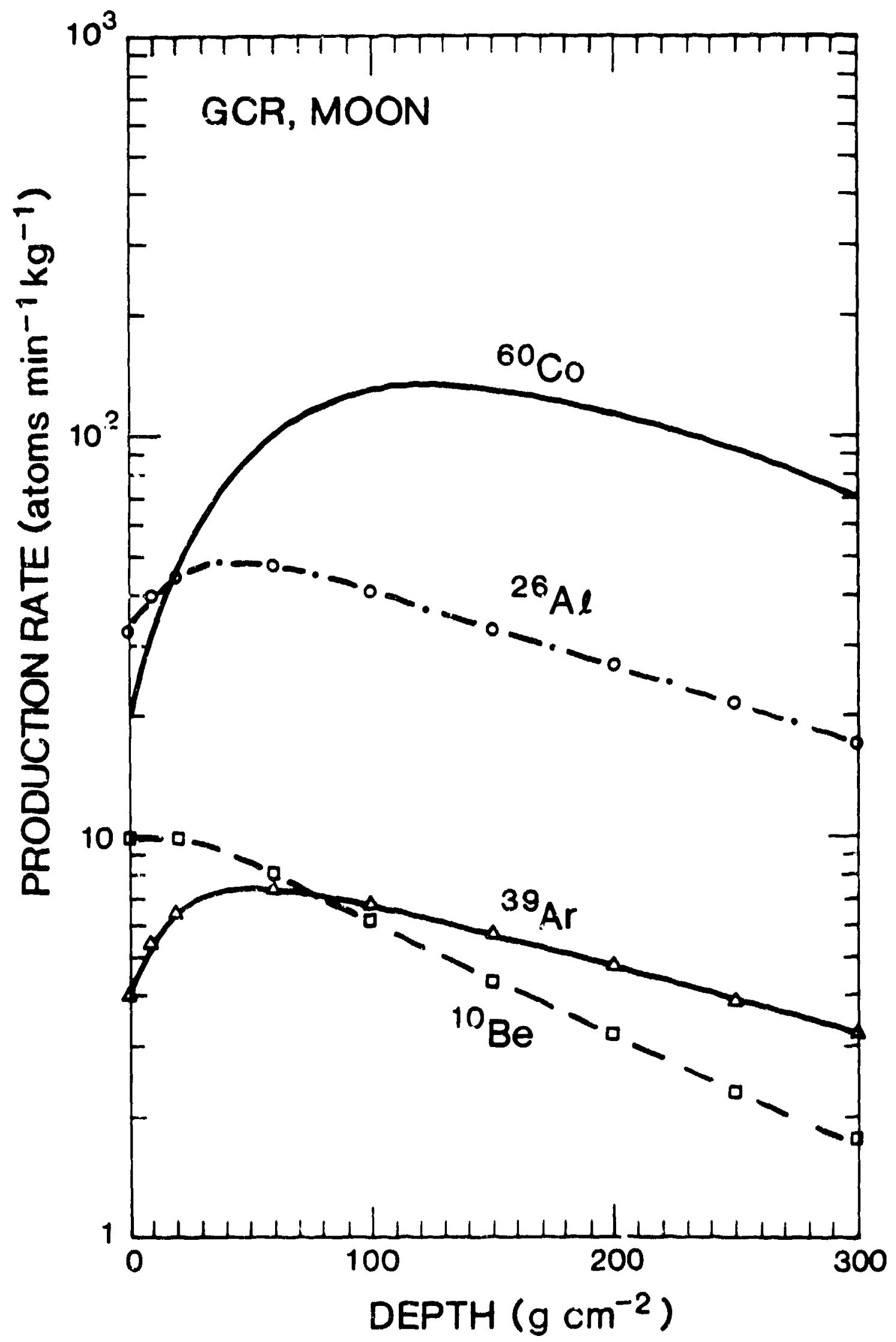

Fig. 4 


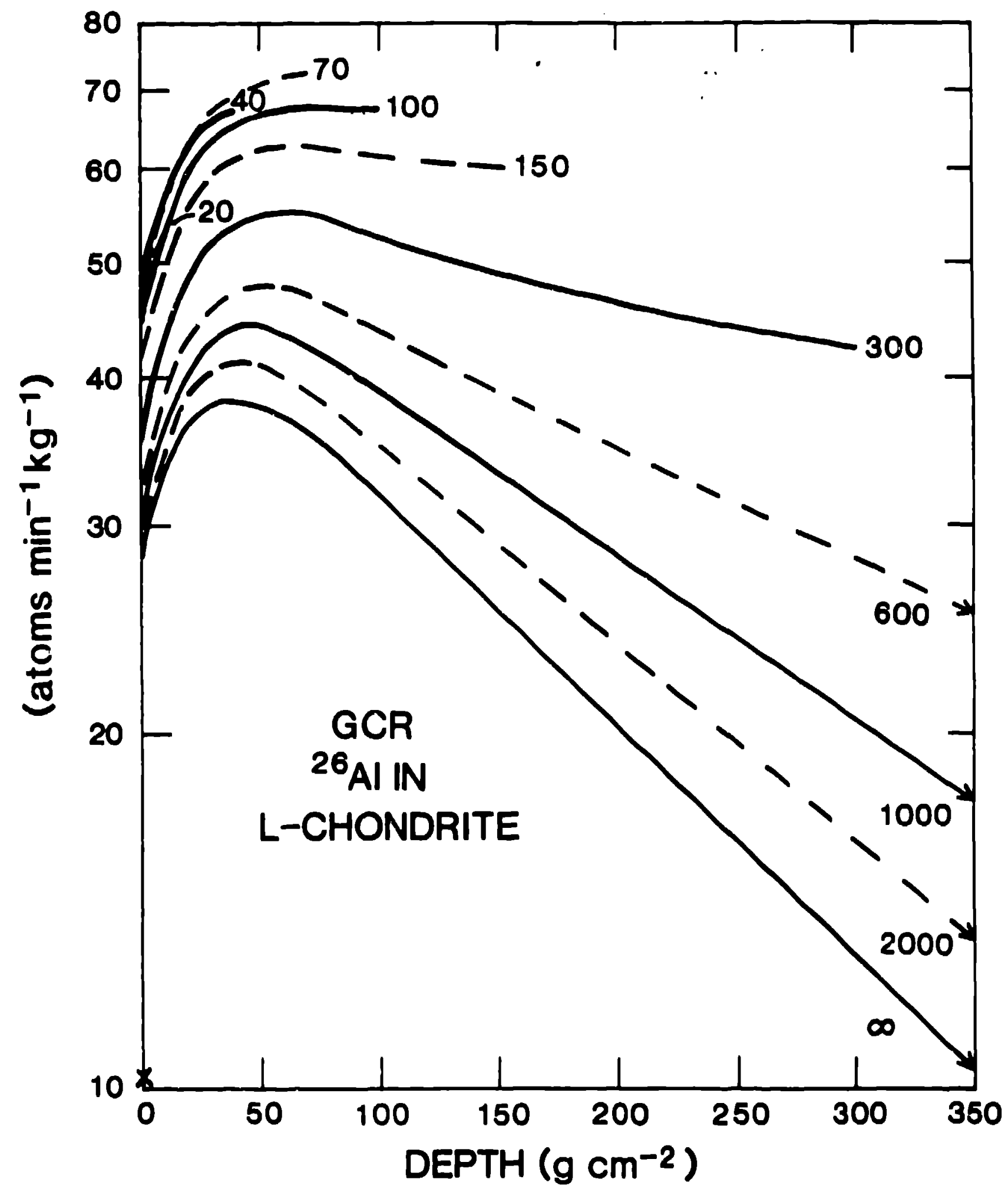

Fig. 5 